\title{
Low preoperative hepcidin concentration as a risk factor for mortality after cardiac surgery: A pilot study
}

\author{
Anja Haase-Fielitz, PharmD, ${ }^{\mathrm{a}}$ Michael Plaß, MD, ${ }^{\mathrm{c}}$ Hermann Kuppe, $\mathrm{MD},{ }^{\mathrm{c}}$ Roland Hetzer, $\mathrm{MD},{ }^{\mathrm{d}}$ \\ Vaughn Ostland, PhD, ${ }^{\mathrm{e}}$ Sabine Westphal, MD, ${ }^{\mathrm{b}}$ Juliane Hoffmann, MD, ${ }^{\mathrm{b}}$ John Prowle, MD ${ }^{\mathrm{f}}$ \\ Peter Rene Mertens, MD, ${ }^{\mathrm{a}}$ Mark Westerman, PhD, ${ }^{\mathrm{e}}$ Rinaldo Bellomo, $\mathrm{MD},{ }^{\mathrm{f}}$ and Michael Haase, $\mathrm{MD}^{\mathrm{a}}$
}

\begin{abstract}
Objective: Hepcidin regulates iron absorption and recycling and is central to host defense, protection from reactive iron species, and a biomarker of iron-related pathophysiology. We assessed the value of hepcidin measured preoperatively for the prediction of in-hospital mortality and renal outcomes.
\end{abstract}

\begin{abstract}
Methods: We studied 100 adult patients undergoing cardiac surgery in the control arm of a randomized, controlled trial. Plasma and urine were sampled before induction of anesthesia, and hepcidin- 25 was quantified by competitive enzyme-linked immunoassay. Renal outcomes were acute kidney injury defined by risk, injury, failure, loss of function, end-stage renal disease (RIFLE) classification and need for renal replacement therapy. Variables with the potential to influence hepcidin expression were investigated.
\end{abstract}

Results: Low preoperative hepcidin concentration in urine (median, $15.3 \mathrm{ng} / \mathrm{mL} ; 25-75$ percentiles, 0-129.1) and plasma (median, $49.2 \mathrm{ng} / \mathrm{mL}$; 25th-75th percentile, 0-52.2) predicted mortality (area under the curve-receiver operating characteristic [AUC-ROC] for urine hepcidin, $0.89 ; 95 \%$ confidence interval, 0.73-0.99; cutoff, $130 \mathrm{ng} / \mathrm{mL}$; sensitivity, $73 \%$; specificity, 100\%; and AUC-ROC for plasma hepcidin, 0.90; 95\% confidence interval, 0.80-0.99; cutoff, $55 \mathrm{ng} / \mathrm{mL}$; sensitivity, 83\%; specificity, 100\%). Survivors had median preoperative hepcidin concentrations of $325.3 \mathrm{ng} / \mathrm{mL}$ (25th-75th percentile, $120-770.1 \mathrm{ng} / \mathrm{mL}$ ) in urine and $113.1 \mathrm{ng} / \mathrm{mL}$ (25th-75th percentile, $77.7-203.1 \mathrm{ng} / \mathrm{mL}$ ) in plasma. Preoperative serum creatinine did not predict mortality (AUC-ROC, 0.50; 95\% confidence interval, 0.10-0.94). Furthermore, preoperative urine, plasma hepcidin, and serum creatinine did not distinguish patients requiring postoperative renal replacement therapy from those without (urine: AUC-ROC, 0.62; 95\% confidence interval, 0.38-0.86; plasma: AUC-ROC, 0.63; 95\% confidence interval, 0.34-0.91; serum creatinine: AUC-ROC, 0.61; 95\% confidence interval, 0.22-0.99). Preoperative renal function and hemoglobin did not correlate with hepcidin indices whereas plasma markers of inflammation did.

Conclusions: Low preoperative hepcidin concentration might be a risk factor for in-hospital mortality. Findings should be validated in larger patient cohorts with a greater number of events. (J Thorac Cardiovasc Surg 2013;145:1380-6)

Cardiac surgery with cardiopulmonary bypass $(\mathrm{CPB})$ is one of the most common major surgical procedures worldwide and improves quality of life and long-term survival. ${ }^{1}$ However, CPB facilitates labile iron toxicity through hemolysis and generation of oxidoinflammation. ${ }^{2,3}$ Iron is an essential trace element for molecules sensing, transporting, and storing oxygen, and for enzymes involved in the oxidation

\footnotetext{
From the Department of Nephrology and Hypertension, Diabetes \& Endocrinology and the Institute of Clinical Chemistry and Pathobiochemistry, ${ }^{\mathrm{b}}$ Otto-vonGuericke-University Magdeburg, Germany; the Institute of Anesthesiology, ${ }^{\mathrm{c}}$ German Heart Center, Berlin, Germany; the Department of Cardiothoracic Surgery, ${ }^{d}$ German Heart Center, Berlin, Germany; Intrinsic LifeSciences, ${ }^{\mathrm{e}}$ La Jolla, Calif; and the Department of Intensive Care ${ }^{\mathrm{f}}$ Austin Health, Melbourne, Australia.

The study was supported by a grant from the German Heart Foundation (Deutsche Stiftung für Herzforschung) and from the Else Kröner-Fresenius-Stiftung, Germany.

Disclosures: Dr Westerman is a shareholder, president, and chief executive officer of Intrinsic LifeSciences; and developer and distributor of an enzyme-linked immunosorbent assay for hepcidin. Dr Westerman has received consulting fees and grant support from Centocor-Ortho Research and Development. Prof Bellomo and Dr Prowle are named in a U.S. preliminary patent application in conjunction with
}

and reduction of substrates and the generation of reactive oxygen for host defense. ${ }^{4}$

Novel biomarkers involved in central iron homeostasis may prove useful in the early identification of patients at increased risk for postoperative adverse events. The peptide hormone hepcidin is the principal regulator of iron absorption and tissue distribution, with gene regulation being

Dr Westerman. Prof Bellomo has received consulting fees from Gambro, Biosite, Abbott Diagnostics, and Philips Medical Systems, and grant support from Fresenius Kabi, Bard, Pfizer, and Gambro. Dr Haase received lecture fees from Abbott Diagnostics and Biosite/Alere. All other authors have nothing to disclose with regard to commercial support.

Received for publication May 14, 2012; revisions received July 26, 2012; accepted for publication Sept 12, 2012; available ahead of print Oct 11, 2012.

Address for reprints: Anja Haase-Fielitz, PharmD, Department of Nephrology and Hypertension, Diabetes \& Endocrinology, Otto-von-Guericke-University Magdeburg, Leipziger St. 44, 39120 Magdeburg, Germany (E-mail: anja. haase-fielitz@med.ovgu.de).

$0022-5223 / \$ 36.00$

Copyright (C) 2013 by The American Association for Thoracic Surgery

http://dx.doi.org/10.1016/j.jtcvs.2012.09.003 


$$
\begin{aligned}
& \text { Abbreviations and Acronyms } \\
& \begin{aligned}
\mathrm{AKI} & =\text { acute kidney injury } \\
\mathrm{CI} & =\text { confidence interval } \\
\mathrm{CKD} & =\text { chronic kidney disease } \\
\mathrm{CPB} & =\text { cardiopulmonary bypass } \\
\mathrm{CRP} & =\text { C-reactive protein } \\
\mathrm{eGFR} & =\text { estimated glomerular filtration rate } \\
\mathrm{IL} & =\text { interleukin } \\
\mathrm{RRT} & =\text { renal replacement therapy }
\end{aligned}
\end{aligned}
$$

influenced by iron loading, hypoxia, or inflammation. ${ }^{5-7}$ Hepcidin is a low-molecular weight peptide $(2.78 \mathrm{kD})$; it passes through the glomerular membrane and is reabsorbed and degraded in the proximal tubules with only a small fraction $(3-5 \%)$ of the filtered hepcidin passing intact into urine. ${ }^{8}$ Therefore, hepcidin concentrations in biofluid may indicate disorders of iron metabolism and may be associated with prognosis. Recently, several work groups found early postoperative hepcidin to be useful in predicting protection from acute kidney injury (AKI) after CPB. ${ }^{9-12}$ These studies provide further support for the role of labile ironassociated reactive oxygen species in the pathophysiology of AKI after the use of CPB in light of the demonstrated utility of other iron-associated protein biomarkers (eg, neutrophil gelatinase-associated lipocalin, liver-type fatty acid-binding protein, cystatin $\mathrm{C}$ ) for the prediction of tubular damage. ${ }^{2}$ The need for improved preoperative risk prediction, the central biologic role of hepcidin, and the importance of CPB in augmenting labile iron-induced organ toxicity suggest hepcidin may have value as a biomarker for risk stratification.

In this study, we aimed (1) to assess the predictive value of preoperative urine and plasma hepcidin concentration for in-hospital mortality, need for renal replacement therapy (RRT) initiation, and the development of AKI; and (2) to investigate modifiers of hepcidin, including preoperative chronic kidney disease (CKD), concentrations of hemoglobin, and markers of inflammation.

\section{METHODS \\ Patient Population}

For the purpose of the study, we took advantage of the control arm of a multicenter, randomized, controlled trial $(\mathrm{N}=100)$ at its German study center (www.clinicaltrials.gov, NCT00672334). This study compared perioperative sodium bicarbonate versus placebo (sodium chloride $0.9 \%$ ) for the prevention of AKI and the exploration of renal biomarkers in patients at increased renal risk undergoing cardiac surgery necessitating the use of CPB.

$\mathrm{CKD}$ was defined as a preoperative estimated glomerular filtration rate (eGFR) $<60 \mathrm{~mL} / \mathrm{min} / 1.73 \mathrm{~m}^{2}{ }^{13}$ eGFR was estimated using the CKD Epidemiology Collaboration equation ${ }^{14}$ using serum creatinine values standardized to isotope dilution mass spectroscopy. RRT was initiated if the patient fulfilled at least 1 of the following clinical criteria: oliguria (urine output, $<100 \mathrm{~mL} />6$ hours) unresponsive to fluid resuscitation measures, hyperkalemia $(\mathrm{K}>6.5 \mathrm{mmol} / \mathrm{L})$, severe acidosis $(\mathrm{pH}<7.2)$, or clinically significant organ edema (eg, lung) in the setting of AKI.

Samples of ethylenediamine tetraacetic acid-plasma and urine were obtained simultaneously directly after insertion of an arterial line before induction of anesthesia. Aliquots of plasma and urine were stored frozen at $-80^{\circ} \mathrm{C}$ immediately after collection and centrifugation, and were kept frozen on dry ice during transport. Patients were recruited between January 2009 and June 2010. The local institutional review board approved this study and written informed consent was obtained from each patient including the investigation of novel renal biomarkers. The study was carried out in compliance with the Helsinki Declaration.

\section{Data Collection and Outcome Definition}

Demographic and clinical data were collected at baseline and during the patient's stay in the intensive care unit. Serum creatinine was measured at baseline and daily within the first postoperative week and, if required, until hospital discharge. AKI was defined based on the baseline-to-peak serum creatinine increase $(>50 \%)$ or urine output decrease $(<0.5 \mathrm{~mL} / \mathrm{kg} / \mathrm{hour}$ for at least 6 hours) during the first 7 postoperative days using the risk, injury, failure, loss of function, end-stage renal disease (RIFLE) consensus definition. ${ }^{15}$ The value of this AKI definition has been reported previously. ${ }^{16,17}$ As mentioned, RRT was initiated if the patient fulfilled at least 1 of the following clinical criteria: oliguria (urine output, $<100 \mathrm{~mL} /$ $>6$ hours) unresponsive to fluid resuscitation measures, hyperkalemia (K $>6.5 \mathrm{mmol} / \mathrm{L}$ ), severe acidosis ( $\mathrm{pH}<7.2)$, or clinically significant organ edema (eg, lung) in the setting of renal failure. Mortality was defined as in-hospital death during the primary postoperative hospital stay. The Strengthening the Reporting of Observational Studies in Epidemiology recommendations ${ }^{18}$ for reporting observational studies were used.

\section{Biochemical Analysis}

Co-investigators performing hepcidin assays (M.W., V.O.) were blinded to patient details and outcomes. Human urine and plasma hepcidin-25 isoforms were measured by competitive enzyme-linked immunoassay in duplicate, as described previously. ${ }^{8}$ The lower limit of hepcidin detection was $5.5 \mathrm{ng} / \mathrm{mL}$. The median coefficient of variation was $<10 \%$ for intraassay precision and $6 \%$ for interassay reproducibility. Urine hepcidin adjusted to urine creatinine was calculated and expressed as nanograms hepcidin per milligrams creatinine. Serum creatinine assays were carried out using the modified Jaffé method. Fractional excretion of hepcidin (ie, the proportion of filtered hepcidin that appears in urine) was calculated by the following formula:

$$
\mathrm{FE}_{\text {hepcidin }}=\left(\left[\mathrm{U}_{\text {hepcidin }}\right] \times\left[\mathrm{Pl}_{\text {creat }}\right] /\left[\mathrm{Pl}_{\text {hepcidin }}\right] \times\left[\mathrm{U}_{\text {creat }}\right]\right) \times 100 \%
$$

where $\mathrm{FE}$ is the fractional excretion, $\mathrm{U}_{\text {hepcidin }}$ is the urine hepcidin concentration, $\mathrm{Pl}_{\text {hepcidin }}$ is the plasma hepcidin concentration, $\mathrm{Pl}_{\text {creat }}$ is the plasma creatinine concentration, and $\mathrm{U}_{\text {creat }}$ is the urine creatinine concentration.

In preoperative samples, we measured interleukin (IL) 6 in urine and plasma by means of enzyme-linked immunosorbent assay (IL-6; ECLIA, Roche Diagnostics, Mannheim, Germany) or immunoturbidimetry for Creactive protein (CRP; ECLIA, Roche Diagnostics) in plasma. The coefficient of variation for each assay was $<10 \%$.

\section{Statistics}

Statistical analysis was performed using SPSS 16.0 (SPSS Inc, Chicago, Ill) and MedCalc 11.5 (Mariakerke, Belgium). Categorical data were reported as percentages with the $95 \%$ confidence interval (CI) of the mean percentage, and compared using the Fisher exact test. After testing for normal distribution, continuous data were reported as median with 25 th to 75 th percentiles, and nonparametric data were compared using the Mann-Whitney $U$ test. We used nonparametric bivariate correlation and report Spearman correlation coefficients. The ability of hepcidin to predict in-hospital mortality, RRT, or AKI was assessed by plotting receiver operating characteristic 
TABLE 1. Preoperative characteristics of patients

\begin{tabular}{|c|c|c|c|c|c|c|}
\hline Variables & $\operatorname{Died}(\mathbf{n}=\mathbf{3})$ & Survived $(\mathbf{n}=97)$ & $P$ value & $\operatorname{RRT}(\mathbf{n}=\mathbf{5})$ & No RRT $(\mathbf{n}=95)$ & $P$ value \\
\hline Age, y; median (25th-75th percentile) & $71(69-75)$ & $68(57-74)$ & 41 & $75(71-77)$ & $68(56-73)$ & .05 \\
\hline Female, $\mathrm{n}(\%)$ & $2(67)$ & $31(32)$ & .25 & $2(40)$ & $31(33)$ & $>.99$ \\
\hline Weight, kg; median (25th-75th percentile) & $75(59-85)$ & $79(67-89)$ & .55 & $80(62-101)$ & $78(67-87)$ & .76 \\
\hline Preoperative chronic kidney disease, $\mathrm{n}(\%)$ & $2(67)$ & $24(2)$ & .17 & $3(60)$ & $23(24)$ & .11 \\
\hline $\begin{array}{l}\text { Serum creatinine, } \mu \mathrm{mol} / \mathrm{L} \text {; median } \\
\quad(25 \text { th- } 75 \text { th percentile })\end{array}$ & $88(53-141)$ & $87(78-106)$ & $>.99$ & $121(63-190)$ & $87(78-105)$ & .38 \\
\hline $\begin{array}{l}\text { Urine creatinine, } g / 24 \text { hours; median } \\
\text { ( } 25 \text { th- } 75 \text { th percentile) }\end{array}$ & $0.92(0.39-1.08)$ & $1.14(0.57-1.77)$ & .33 & $0.93(0.55-1.64)$ & $1.14(0.57-1.74)$ & .68 \\
\hline Hemoglobin, g/dL; median (25th-75th percentile) & $11.4(11.3-14.3)$ & $12.6(11.3-14.0)$ & .82 & $11.2(9.1-12.9)$ & $12.6(11.3-14.0)$ & .10 \\
\hline Preoperative LVEF <35\%, n (\%) & $2(67)$ & $9(9)$ & .031 & $1(20)$ & $10(11)$ & .45 \\
\hline Arterial hypertension, $\mathrm{n}(\%)$ & $2(67)$ & $71(73)$ & $>.99$ & $4(80)$ & $69(73)$ & $>.99$ \\
\hline Hypercholesterolemia, n (\%) & $3(100)$ & $61(63)$ & .55 & $3(60)$ & $61(63)$ & $>.99$ \\
\hline Chronic obstructive pulmonary disease, $\mathrm{n},(\%)$ & $0(0)$ & $11(11)$ & $>.99$ & $1(20)$ & $10(11)$ & .45 \\
\hline Diabetes mellitus, $\mathrm{n}(\%)^{*}$ & $2(67)$ & $18(19)$ & .10 & $1(20)$ & $19(20)$ & $>.99$ \\
\hline Atrial fibrillation, $\mathrm{n}(\%) \dagger$ & $2(67)$ & $28(29)$ & .21 & $3(60)$ & $27(28)$ & .16 \\
\hline Peripheral vascular disease, $\mathrm{n}(\%)$ & $1(33)$ & $20(21)$ & .52 & $0(0)$ & $21(22)$ & .58 \\
\hline ACE-inhibitors/ATRB, n (\%) & $3(100)$ & $51(52)$ & .25 & $4(80)$ & $50(53)$ & .37 \\
\hline$\beta$-blocker, $\mathrm{n}(\%)$ & $3(100)$ & $69(70)$ & .56 & $4(80)$ & $68(72)$ & $>.99$ \\
\hline Statins, n (\%) & $2(67)$ & $51(52)$ & $>.99$ & $3(60)$ & $50(53)$ & $>.99$ \\
\hline Diuretics, n (\%) & $3(100)$ & $56(58)$ & .27 & $4(80)$ & $55(58)$ & .40 \\
\hline
\end{tabular}

$R R T$, Renal replacement therapy; $L V E F$, left ventricular ejection fraction; $A C E$, angiotensin-converting enzyme; $A T R B$, angiotensin II receptor blocker. *Diabetes mellitus is defined as patients with diabetes on medication (insulin or oral antidiabetics). †Atrial fibrillation (AF) was defined as paroxysmal, persistent, or permanent AF with first time episodes of AF counted as no AF.

(ROC) curves, and further reported as area under the curve (AUC) with $95 \%$ CIs. An AUC-ROC value of $>0.7$ was taken to indicate a reasonable performance and $>0.8$ indicated a good biomarker performance. ${ }^{19}$ ROC optimal cutoff values with a statistically significant AUC were defined as the point that maximized the combination of sensitivity and specificity. Statistical significance was denoted by 2 -sided $P$ values of $<.05$.

\section{RESULTS}

\section{Patient Characteristics}

Preoperative characteristics are presented in Tables 1 and 2. Survivors or patients who did not require RRT were younger, more likely to be male, had fewer preoperative comorbidities including CKD and atrial fibrillation, and a trend to a shorter duration of CPB (Tables 1 and 2). Type of operation did not differ among all patients. Survivors and those who did not require RRT received more fluids; however, lower volumes of blood transfusion and doses of furosemide, and had a preserved diuresis within the first 24 hours postoperatively (Table 2 ). In our cohort, all patients who died developed AKI, with 1 patient requiring RRT. Two patients died of cardiogenic shock and 1 died of sepsis. Patients who died or required RRT had a 2.5-day longer stay in the intensive care (Table 2). RRT was initiated in 3 patients as a result of AKI and in 2 patients as a result of anuria for $<6$ hours and preoperative CKD.

\section{Preoperative Value of Hepcidin for In-Hospital Mortality}

Survivors had a 20-times higher median preoperative urine hepcidin concentration compared with nonsurvivors
$(P=.020 ;$ Figure $1, A)$. This difference translated in an AUC-ROC for the prediction of postoperative mortality of 0.89 with a cutoff of $130 \mathrm{ng} / \mathrm{mL}$, a sensitivity of $73 \%$, and a specificity of $100 \%$ (Figure 2, A). They also had 2-times higher preoperative plasma hepcidin concentrations compared with nonsurvivors $(P=.013$; Figure $1, B)$. Preoperative plasma hepcidin concentration was a good predictor of mortality, with an AUC-ROC of 0.90, a cutoff of $55 \mathrm{ng} /$ $\mathrm{mL}$, a sensitivity of $83 \%$, and a specificity of $100 \%$ (Figure 2, A). The predictive value for mortality was in the same magnitude for preoperative fractional hepcidin excretion (AUC-ROC, 0.90; 95\% CI, 0.77-0.99; cutoff, $1.31 \%$; sensitivity, $81 \%$; specificity, $100 \%$ ) and for preoperative urine hepcidin adjusted to urine creatinine (AUC-ROC, 0.89; 95\% CI, 0.78-0.99; cutoff, $120 \mathrm{ng} / \mathrm{mg}$; sensitivity, $77 \%$; specificity, $100 \%$ ). Both preoperative serum creatinine and eGFR did not predict mortality (AUC-ROC, 0.50; 95\% CI, 0.10-0.94 and AUC-ROC, $0.62 ; 95 \%$ CI, 0.25-0.98, respectively.

\section{Preoperative Value of Hepcidin for Renal Outcome}

Preoperative urine and plasma hepcidin concentrations were similar in patients requiring RRT or not $(P=.37$ and $P=.35$, respectively; Figure $3, A$ and $B$ ). Both markers (Figure $2, B$ ) as well as serum creatinine concentration or eGFR could not discriminate patients requiring postoperative RRT (urine hepcidin AUC-ROC, 0.62; plasma hepcidin AUC-ROC, 0.63; fractional hepcidin excretion AUC-ROC, $0.51 ; 95 \%$ CI, 0.20-0.77; urine hepcidin adjusted to urine creatinine AUC-ROC, 0.64; 95\% CI, 0.37-0.91; serum 
TABLE 2. Interventions and outcomes

\begin{tabular}{|c|c|c|c|c|c|c|}
\hline Variables & $\operatorname{Died}(\mathbf{n}=3)$ & Survived $(\mathrm{n}=\mathbf{9 7})$ & $P$ value & RRT $(\mathbf{n}=\mathbf{5})$ & No RRT $(\mathbf{n}=95)$ & $P$ value \\
\hline CABG surgery, $\mathrm{n}(\%)$ & $1(33)$ & $18(19)$ & .47 & $1(20)$ & $18(19)$ & $>.99$ \\
\hline Valve surgery, $\mathrm{n}(\%)$ & $1(33)$ & $49(51)$ & $>.99$ & $2(40)$ & $48(51)$ & $>.99$ \\
\hline CABG and valve surgery, $\mathrm{n}(\%)$ & $1(33)$ & $23(24)$ & .57 & $2(40)$ & $22(23)$ & .59 \\
\hline Thoracic aortic surgery, $\mathrm{n}(\%)$ & $0(0)$ & $7(7)$ & $>.99$ & $0(0)$ & $7(7)$ & $>.99$ \\
\hline Previous cardiothoracic operation, $\mathrm{n}(\%)$ & $0(0)$ & $28(29)$ & .56 & $0(0)$ & $28(29)$ & .32 \\
\hline $\begin{array}{l}\text { Duration of bypass, min; median } \\
\quad \text { (25th-75th percentile) }\end{array}$ & $131(125-274)$ & $118(91-159)$ & .18 & $125(107-217)$ & $119(91-158)$ & .29 \\
\hline \multicolumn{7}{|l|}{ Within the first 24 hours postoperatively } \\
\hline Fluid input, $\mathrm{mL}$; median (25th-75th percentile)* & $2810(1030-7360)$ & $8130(6520-9640)$ & .036 & $5500(3180-7290)$ & $8160(6590-9680)$ & .021 \\
\hline Urine output, mL; median ( 25 th- 75 th percentile) & $3450(2430-5010)$ & $5170(4240-6540)$ & .048 & $4000(2880-6100)$ & $5150(4300-6500)$ & .20 \\
\hline Blood transfusion, $\mathrm{n}(\%)$ & $3(100)$ & $53(55)$ & .27 & $4(80)$ & $52(55)$ & .38 \\
\hline $\begin{array}{l}\text { Blood transfusion, } \mathrm{mL} \text {; median } \\
\quad(25 \text { th-75th percentile })\end{array}$ & $4250(500-5900)$ & $250(0-500)$ & .017 & $1000(250-3500)$ & $250(0-500)$ & .079 \\
\hline $\begin{array}{l}\text { Other blood products, } \mathrm{mL} \text {; median } \\
\text { (25th-75th percentile) } \dagger\end{array}$ & $7550(0-13,300)$ & $330(0-1210)$ & .13 & $2860(1400-8470)$ & $0(0-880)$ & .001 \\
\hline Furosemide, $\mathrm{n}(\%)$ & $2(67)$ & $70(72)$ & $>.99$ & $4(80)$ & $68(72)$ & $>.99$ \\
\hline Furosemide, mg; median (25th-75th percentile) & $80(0-270)$ & $20(0-40)$ & .25 & $80(30-280)$ & $20(0-40)$ & .023 \\
\hline Vasopressor use, n (\%) & $2(67)$ & $67(69)$ & $>.99$ & $4(80)$ & $65(68)$ & $>.99$ \\
\hline Inotrope use, $\mathrm{n}(\%)$ & $3(100)$ & $56(58)$ & .27 & $5(100)$ & $54(57)$ & .076 \\
\hline $\begin{array}{l}\text { Length of stay in intensive care, hours; median } \\
\text { (25th-75th percentile) }\end{array}$ & $81.1(74.6-148.7)$ & $26.3(22.6-70.1)$ & .090 & $81.1(35.9-410.9)$ & $26.3(22.6-71.1)$ & .050 \\
\hline AKI defined by RIFLE, n (\%) & $3(100)$ & $6(6)$ & .001 & $3(60)$ & $6(6)$ & .005 \\
\hline Need for RRT, n (\%) & $1(33)$ & $4(4)$ & .023 & - & - & - \\
\hline Hospital mortality, n (\%) & - & - & - & $1(20)$ & $2(2)$ & .023 \\
\hline
\end{tabular}

$R R T$, Renal replacement therapy; $C A B G$; coronary artery bypass grafting; $A K I$, acute kidney injury; RIFLE, risk, injury, failure, loss of function, end-stage renal disease. *Including crystalloids and colloids. $\dagger$ Including fresh-frozen plasma, platelets, and cryoprecipitates.

creatinine AUC-ROC, 0.61; 95\% CI, 0.22-0.99; and eGFR AUC-ROC, 0.66; 95\% CI, 0.33-0.98).

Furthermore, preoperatively, patients not developing AKI presented with nonsignificant higher urine and plasma hepcidin concentrations compared with patients developing AKI later (Figure 4). This difference did not translate in a good predictive value for postoperative AKI (urine hepcidin AUC-ROC, 0.68; plasma hepcidin AUC-ROC, 0.67; Figure $2, C$ ). Also, preoperatively, fractional hepcidin excretion (AUC-ROC, 0.65; 95\% CI, 0.46-0.83), urine hepcidin adjusted to urine creatinine (AUC-ROC, 0.69; 95\% CI, 0.51-0.87), serum creatinine (AUC-ROC, 0.56; 95\% CI, 0.34-0.78), or eGFR (AUC-ROC, 0.62; 95\% CI, 0.420.82 ) could not predict the development of AKI.

\section{Renal Function, Hemoglobin, Inflammation Markers, and Preoperative Hepcidin}

Preoperative eGFR did not correlate with preoperative urine and plasma hepcidin indices (all Spearman correlation coefficients $<0.20$ ). Results did not change after adjustment to urine creatinine (Table 3 ). Baseline eGFR correlated with plasma markers of inflammation (Spearman- $\rho$ coefficients for IL-6, $-0.40 ; P=.009$ and for CRP, $-0.34 ; P=.025$ ) and with preoperative hemoglobin concentration (Spearman- $\rho$ coefficient, $0.34 ; P=.001$ ).

Although, patients surviving or not requiring RRT had a trend for higher preoperative hemoglobin concentrations
(Table 1), hemoglobin did not correlate with preoperative hepcidin indices (Table 3). Preoperative plasma IL-6 and CRP but not urine IL-6 correlated significantly with fractional hepcidin excretion and urine hepcidin adjusted for urine creatinine (Table 3 ).

\section{DISCUSSION}

In a small pilot study of 100 patients undergoing cardiac surgery, we found that low preoperative urine and plasma hepcidin concentrations were predictors of in-hospital mortality, although they had no value as predictors of renal outcomes. Preoperative eGFR and hemoglobin did not correlate with hepcidin indices, whereas plasma IL-6 and CRP did.

Hepcidin represents a principal regulator of extracellular iron homeostasis in health and disease, and as such is a promising target for the diagnosis of labile ironmediated disorders. There are already several studies suggesting an important role of hepcidin in modulating and predicting the course and outcome of inflammationmediated diseases. Early postoperative increases in hepcidin concentrations indicated protection from subsequent $\mathrm{AKI}^{9-12}$ and malaria-associated mortality. ${ }^{20}$

Previously, IL-6 was shown to be a prominent systemic inducer of hepcidin expression. ${ }^{4,5,21,22}$ Contrary to these previous observations, we found a weak relationship between plasma concentrations of inflammatory markers 

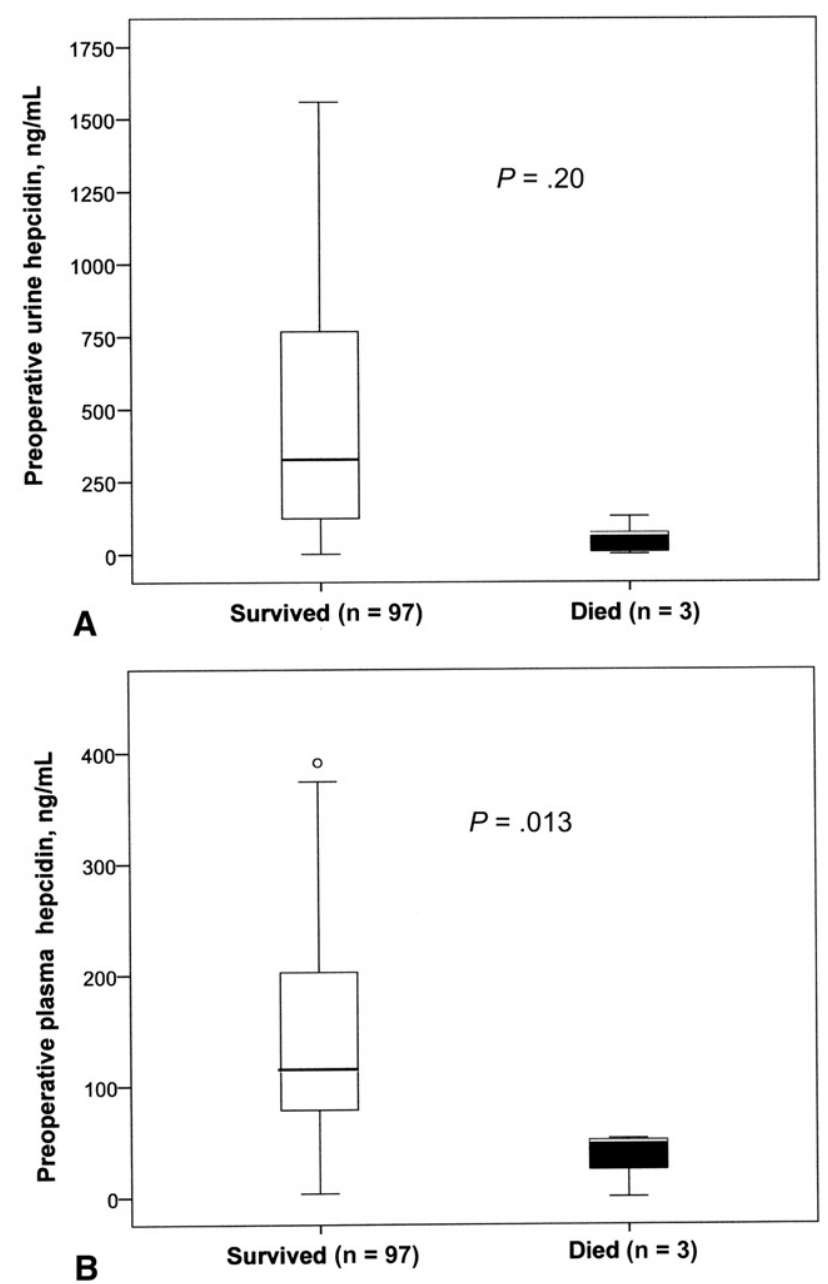

FIGURE 1. Preoperative urine hepcidin (A) and plasma hepcidin (B) concentrations in survivors and nonsurvivors. White boxes indicate median hepcidin concentration in nanograms per milliliter with the 25 th to 75 th percentiles in patients who survived the hospital stay (urine: $325.3 \mathrm{ng} /$ $\mathrm{mL}$; 25th-75th percentile, 120.0-770.1; plasma: $113.1 \mathrm{ng} / \mathrm{mL}$; 25th-75th percentile, 77.7-203.1). Black boxes indicate median hepcidin concentration in nanograms per milliliter with 25 th to 75 th percentiles in those who died (urine: $15.3 \mathrm{ng} / \mathrm{mL}$; 25th-75th percentile, 0-129.1; plasma: $49.2 \mathrm{ng} / \mathrm{mL} ; 25$ th-75th percentile, 0-52.2).

and hepcidin. Upregulation of hepcidin in IL-6 knockout mice with chronic inflammation is similar to wild-type mice, suggesting IL-6-independent pathways of hepcidin stimulation. ${ }^{4,23}$ As an alternative explanation, the absent correlation between urine and plasma hepcidin with proinflammatory markers might confirm previous results in which hepcidin is only upregulated under conditions of overt inflammation ${ }^{22}$ not expected to occur in our patients in a preoperative setting.

The association between hepcidin and inflammatory markers increased when hepcidin indices integrating renal excretory function markers such as fractional excretion or adjustment to urine creatinine were used. The observed
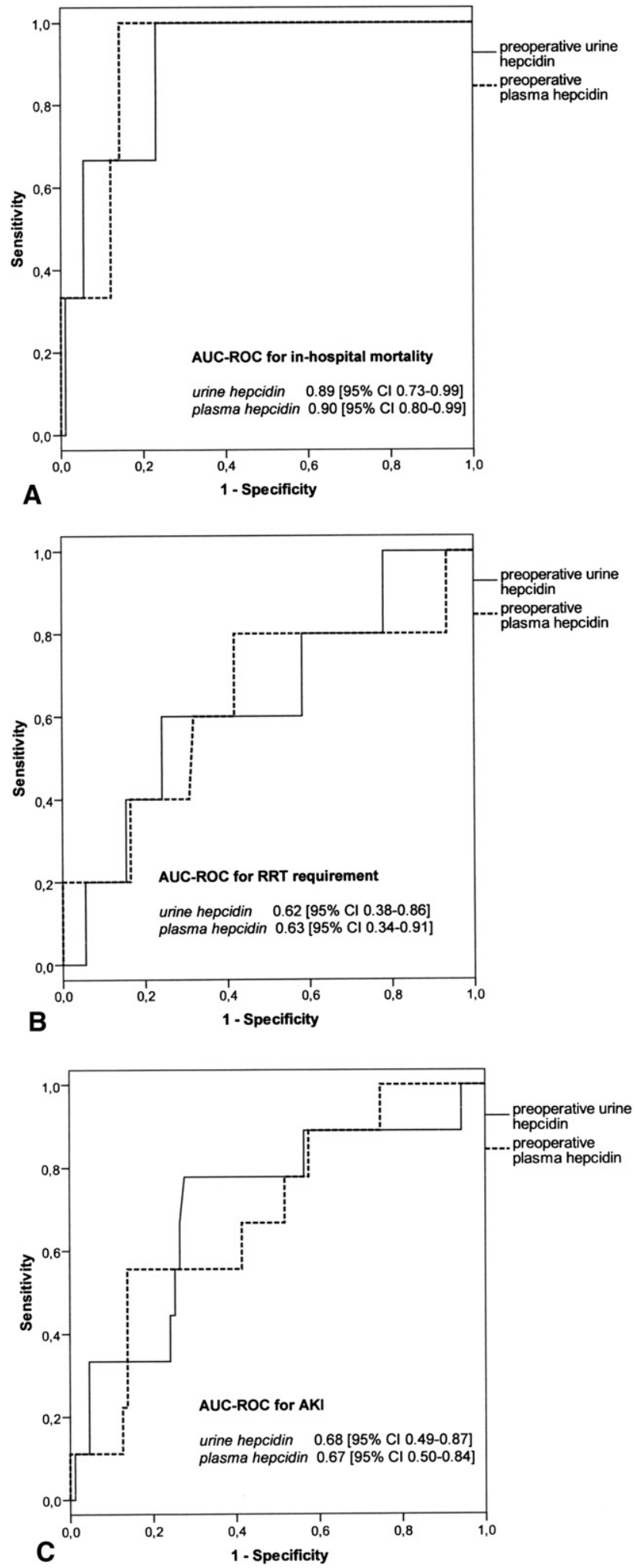

FIGURE 2. Area under the curve-receiver operating characteristic analyses $(A U C-R O C)$ of preoperative urine and plasma hepcidin for in-hospital mortality (A), requirement of postoperative renal replacement therapy $(R R T)$ initiation (B) and acute kidney injury ( $A K I$; risk, injury, failure, loss of function, end-stage renal disease [RIFLE]) (C). $C I$, Confidence interval. 

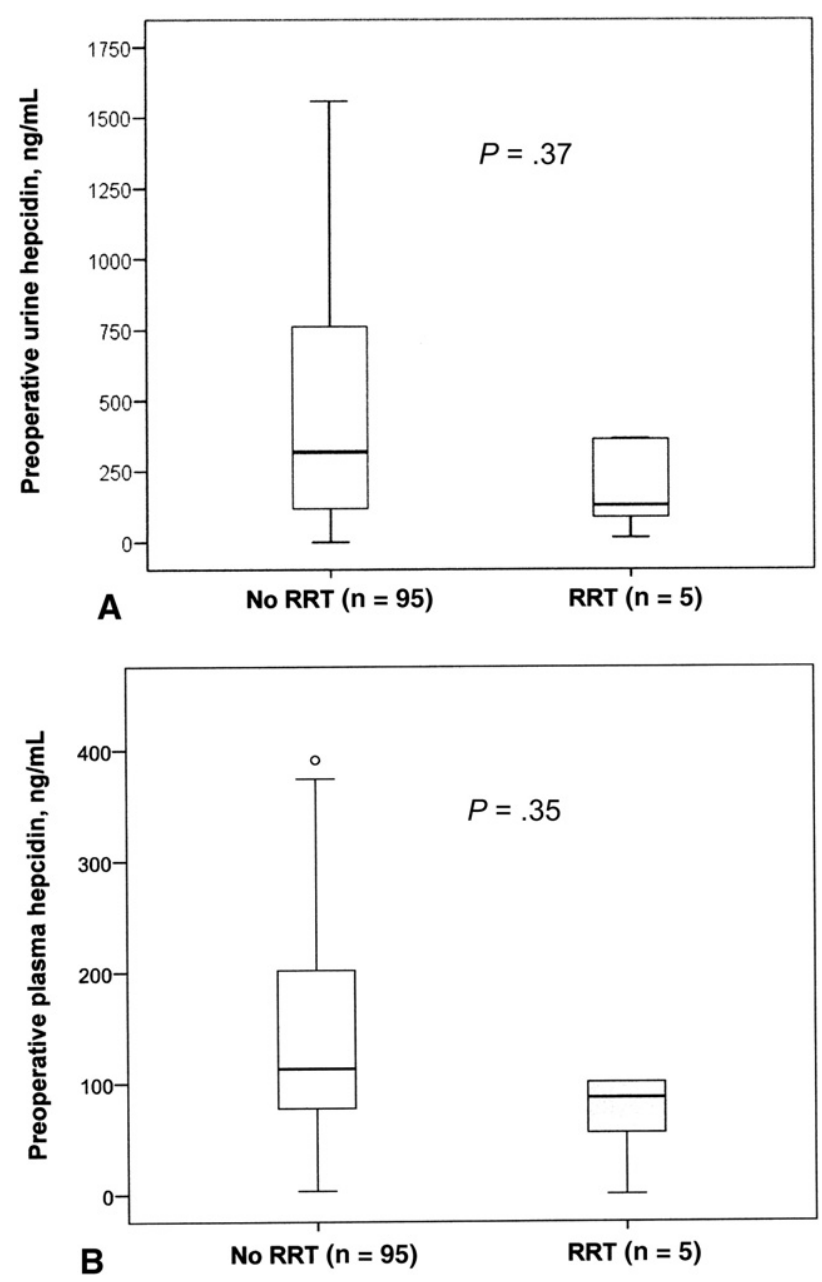

FIGURE 3. Preoperative urine hepcidin (A) and plasma hepcidin (B) concentrations in patients requiring renal replacement therapy $(R R T)$ and in those who did not. White boxes indicate median hepcidin concentration in nanograms per milliliter with 25 th to 75 th percentiles in patients not requiring RRT. Gray boxes indicate median hepcidin concentration in nanograms per milliliter with 25 th to 75 th percentiles in patients with RRT initiation.

correlation of preoperative fractional hepcidin excretion with CRP indicates microinflammation in our patients. Therefore, it is possible that postoperatively declining renal function might potentiate the relationship between inflammation and iron metabolism. Although significant glomerular hepcidin filtration can be expected, our findings are in line with Peters and colleagues, ${ }^{24}$ who recently report that eGFR is not a major determinant of serum hepcidin-25 levels. Unlike previous studies enrolling patients with $\mathrm{CKD},{ }^{25,26}$ we found hepcidin not to be correlated with preoperative hemoglobin levels.

The findings of our pilot study point toward the potential usefulness of preoperative hepcidin measurement for risk assessment. If confirmed, hepcidin might become part of scoring systems applied before cardiac surgery. They also suggest the need to study the biology of hepcidin to

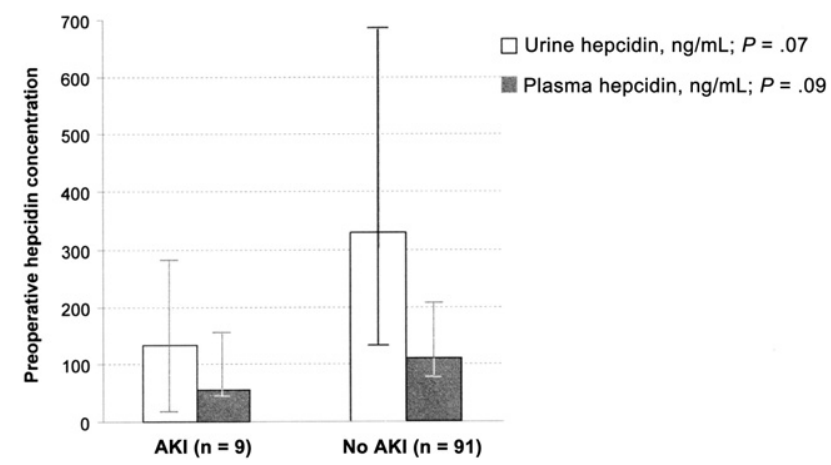

FIGURE 4. Preoperative urine and plasma hepcidin concentrations in patients with acute kidney injury $(A K I)$ and without AKI. White boxes indicate median urine hepcidin concentration in nanograms per milliliter with 25 th to 75 th percentiles (no-AKI: median urine hepcidin concentration, $326.6 \mathrm{ng} / \mathrm{mL}$; 25th-75th percentile, 117.5-692.6; AKI: median urine hepcidin concentration, $133.6 \mathrm{ng} / \mathrm{mL} ; 25$ th-75th percentile, 15.2-263.6). Gray boxes indicate median plasma hepcidin concentration in nanograms per milliliter with 25th to 75th percentiles (no-AKI: median plasma hepcidin concentration, $112.2 \mathrm{ng} / \mathrm{mL}$; 25th-75th percentile, 77.6-203.4; AKI: median plasma hepcidin concentration, $55.2 \mathrm{ng} / \mathrm{mL} ; 25$ th-75th percentile, 50.0-145.7).

understand in greater detail what this marker might tell us about underlying disturbances in iron metabolism and their impact on outcome.

A potential mechanism explaining the negative relationship between low preoperative hepcidin concentration and mortality might be linked to preoperative "subclinical" hypoxia. Hypoxia regulates hepcidin down, causing (free) iron release into plasma ${ }^{4}$ - an effect that might be potentiated during $\mathrm{CPB}$ in affected patients. Misliganded iron and other reactive substances may contribute to clinically detectable organ injury. ${ }^{2}$ All patients who died in hospital in the current study developed postoperative AKI, which was detected by low, early postoperative hepcidin concentration, as previously reported. ${ }^{9}$

Our study has several strengths and limitations. In particular, the simultaneous measurement or calculation of preoperative hepcidin and hepcidin indices and inflammation markers in a relatively homogenous and well-characterized patient cohort enabled detection of a biologically plausible association. However, the number of events was low and the addition of patients with high hepcidin concentration ( $>75$ th percentile of patients who did not die in hospital) who present with an unfavorable outcome (in-hospital death) would have changed the results to borderline or nonsignificant. Therefore, our study can only serve as a pilot investigation to test a new research hypothesis in a small number of subjects. Findings should be validated in larger patient cohorts with greater number of events, making multivariate clinical and biochemical score modeling possible, and aiming at improving existing risk prediction scores applied in cardiac surgery. 
TABLE 3. Correlation of preoperative variables with preoperative hepcidin indices

\begin{tabular}{|c|c|c|c|c|c|c|}
\hline Variables & $\begin{array}{c}\text { Urine } \\
\text { hepcidin }\end{array}$ & Plasma hepcidin & $\begin{array}{l}\text { Urine:plasma } \\
\text { hepcidin ratio }\end{array}$ & $\begin{array}{c}\text { Fractional hepcidin } \\
\text { excretion }\end{array}$ & $\begin{array}{c}\text { Urine hepcidin/urine } \\
\text { creatinine }\end{array}$ & Urine creatinine \\
\hline eGFR & $0.15, P=.15$ & $0.043, P=.67$ & $0.18, P=.11$ & $-0.16, P=.12$ & $0.07, P=.51$ & $0.26, P=.010$ \\
\hline Hemoglobin & $0.13, P=.21$ & $0.06, P=.55$ & $0.14, P=.18$ & $-0.09, P=.38$ & $0.01, P=.93$ & $0.28, P=.005$ \\
\hline Urine IL-6 & $-0.028, P=.78$ & $-0.01, P=.92$ & $-0.078, P=.45$ & $-0.006, P=.95$ & $-0.039, P=.70$ & $-0.012, P=.91$ \\
\hline Plasma IL-6 & $0.19, P=.22$ & $0.09, P=.56$ & $0.19, P=.23$ & $0.49, P=.001$ & $0.31, P=.04$ & $0.24, P=.12$ \\
\hline CRP & $0.22, P=.16$ & $0.18, P=.24$ & $0.16, P=.29$ & $0.43, P=.004$ & $0.33, P=.027$ & $-0.19, P=.22$ \\
\hline
\end{tabular}

Values denote Spearman $\mathrm{r}$ correlation coefficients. $e G F R$, Estimated glomerular filtration rate; $I L$, interleukin: $C R P$, C-reactive protein.

In conclusion, low preoperative hepcidin concentrations are predictive of in-hospital mortality but not of renal outcomes in patients undergoing cardiac surgery. Further validation of this finding is now required.

We thank Argid Rutenberg and Raimund Rutenberg (German Heart Center Berlin, Germany) for their excellent research assistance.

\section{References}

1. Velazquez EJ, Williams JB, Yow E, Shaw LK, Lee KL, Phillips HR, et al. Longterm survival of patients with ischemic cardiomyopathy treated by coronary artery bypass grafting versus medical therapy. Ann Thorac Surg. 2012;93:523-30.

2. Haase M, Bellomo R, Haase-Fielitz A. Novel biomarkers, oxidative stress, and the role of labile iron toxicity in cardiopulmonary bypass-associated acute kidney injury. J Am Coll Cardiol. 2010;55:2024-33.

3. Rosner MH, Okusa MD. Acute kidney injury associated with cardiac surgery. Clin J Am Soc Nephrol. 2006;1:19-32.

4. Ganz T. Molecular control of iron transport. JAm Soc Nephrol. 2007;18:394-400.

5. Ganz T, Nemeth E. Hepcidin and disorders of iron metabolism. Annu Rev Med. 2011;62:347-60.

6. Pigeon C, Ilyin G, Courselaud B, Leroyer P, Turlin B, Brissot P, et al. A new mouse liver-specific gene, encoding a protein homologous to human antimicrobial peptide hepcidin, is overexpressed during iron overload. J Biol Chem. 2001; 276:7811-9.

7. Hunter HN, Fulton DB, Ganz T, Vogel HJ. The solution structure of human hepcidin, a peptide hormone with antimicrobial activity that is involved in iron uptake and hereditary hemochromatosis. J Biol Chem. 2002;277:37597-603.

8. Ganz T, Olbina G, Girelli D, Nemeth E, Westerman M. Immunoassay for human serum hepcidin. Blood. 2008;112:4292-7.

9. Haase-Fielitz A, Mertens PR, Plass M, Kuppe H, Hetzer R, Westerman M, et al. Urine hepcidin has additive value in ruling out cardiopulmonary bypassassociated acute kidney injury: an observational cohort study. Crit Care. 2011; 15. R186.

10. Ho J, Lucy M, Krokhin O, Hayglass K, Pascoe E, Darroch G, et al. Mass spectrometry-based proteomic analysis of urine in acute kidney injury following cardiopulmonary bypass: a nested case-control study. Am J Kidney Dis. 2009;53: 584-95.

11. Ho J, Reslerova M, Gali B, Gao A, Bestland J, Rush DN, et al. Urinary hepcidin25 and risk of acute kidney injury following cardiopulmonary bypass. Clin J Am Soc Nephrol. 2011;6:2340-6.

12. Prowle JR, Ostland V, Calzavacca P, Ligabo EV, Echeverri JE, Bagshaw SM, et al. Greater increase in urinary hepcidin predicts protection from acute kidney injury after cardiopulmonary bypass. Nephrol Dial Transplant. 2012;27:595-602.
13. Levey AS, Eckardt KU, Tsukamoto Y, Levin A, Coresh J, Rossert J, et al. Definition and classification of chronic kidney disease: a position statement from Kidney Disease: Improving Global Outcomes (KDIGO). Kidney Int. 2005;67: 2089-100.

14. Levey AS, Stevens LA, Schmid CH, Zhang YL, Castro AF III, CKD-EPI (Chronic Kidney Disease Epidemiology Collaboration), et al. CKD-EPI (Chronic Kidney Disease Epidemiology Collaboration): a new equation to estimate glomerular filtration rate. Ann Intern Med. 2009;150:604-12.

15. Bellomo R, Ronco C, Kellum JA, Mehta RL, Palevsky P, Acute Dialysis Quality Initiative workgroup. Acute dialysis quality initiative workgroup: acute renal failure: definition, outcome measures, animal models, fluid therapy and information technology needs: the Second International Consensus Conference of the Acute Dialysis Quality Initiative (ADQI) Group. Crit Care. 2004;8:R204-12.

16. Arnaoutakis GJ, Bihorac A, Martin TD, Hess PJ Jr, Klodell CT, Ejaz AA, et al. RIFLE criteria for acute kidney injury in aortic arch surgery. $J$ Thorac Cardiovasc Surg. 2007;134:1554-61.

17. Haase M, Bellomo R, Matalanis G, Calzavacca P, Dragun D, Haase-Fielitz A. A comparison of the RIFLE and Acute Kidney Injury Network classifications for cardiac surgery-associated acute kidney injury: a prospective cohort study. $J$ Thorac Cardiovasc Surg. 2009; 138:1370-6.

18. von Elm E, Altman DG, Egger M, Pocock SJ, Gøtzsche PC, Vandenbroucke JP, STROBE Initiative. The Strengthening the Reporting of Observational Studies in Epidemiology (STROBE) statement: guidelines for reporting observational studies. Lancet. 2007;370:1453-7.

19. Swets JA. Measuring the accuracy of diagnostic systems. Science. 1988;240: 1285-93.

20. Wang HZ, He YX, Yang CJ, Zhou W, Zou CG. Hepcidin is regulated during blood-stage malaria and plays a protective role in malaria infection. J Immunol. 2011;187:6410-6.

21. Theurl I, Aigner E, Theurl M, Nairz M, Seifert M, Schroll A, et al. Regulation of iron homeostasis in anemia of chronic disease and iron deficiency anemia: diagnostic and therapeutic implications. Blood. 2009;113:5277-86.

22. Ferrucci L, Semba RD, Guralnik JM, Ershler WB, Bandinelli S, Patel KV, et al. Proinflammatory state, hepcidin, and anemia in older persons. Blood. 2010;115: 3810-6.

23. Sow FB, Florence WC, Satoskar AR, Schlesinger LS, Zwilling BS, Lafuse WP. Expression and localization of hepcidin in macrophages: a role in host defense against tuberculosis. J Leukoc Biol. 2007;82:934-45.

24. Peters HP, Laarakkers CM, Swinkels DW, Wetzels JF. Serum hepcidin-25 levels in patients with chronic kidney disease are independent of glomerular filtration rate. Nephrol Dial Transplant. 2010;25:848-53.

25. Zaritsky J, Young B, Wang HJ, Westerman M, Olbina G, Nemeth E, et al. Hepcidin: a potential novel biomarker for iron status in chronic kidney disease. Clin J Am Soc Nephrol. 2009;4:1051-6.

26. Ashby DR, Gale DP, Busbridge M, Murphy KG, Duncan ND, Cairns TD, et al. Plasma hepcidin levels are elevated but responsive to erythropoietin therapy in renal disease. Kidney Int. 2009;75:976-81. 